\title{
Neutron diffraction analysis of residual strain/stress distribution in the vicinity of high strength welds
}

\author{
L. Mráz ${ }^{1}$, L. Karlsson ${ }^{2}$, I. Hamák ${ }^{1}$, M. Vrána ${ }^{3}$ and P. Mikula ${ }^{3, a}$ \\ ${ }^{1}$ Welding Research Institute - Industrial Institute SR, Račianska 71, 83259 Bratislava 3, Slovakia \\ ${ }^{2}$ ESAB AB, Göteborg, Sweden \\ ${ }^{3}$ Nuclear Physics Institute ASCR, v.v.i., 25068 Řež, Czech Republic
}

\section{Abstract}

Residual stresses resulting from non homogeneous heat distribution during welding process belong to most significant factor influencing behavior of welded structures. These stresses are responsible for defect occurrence during welding and they are also responsible for crack initiation and propagation at the either static or dynamic load. The significant effect of weld metal chemical composition as well as the effect of fatigue load and local plastic deformation on residual stress distribution and fatigue life have been recognized for high strength steels welds. The changes in residual stress distribution have then positive effect on cold cracking behavior and also on fatigue properties of the welds [1-3]. Several experimental methods, both destructive and non-destructive, such as hole drilling method, X-ray diffraction, neutron diffraction and others, have been used to examine residual stress distribution in all three significant orientations in the vicinity of the welds. The present contribution summarizes the results of neutron diffraction measurements of residual stress distribution in the vicinity of single-pass high-strength-steel welds having different chemical composition as well as the influence of fatigue load and local plastic deformation. It has been observed that the chemical composition of the weld metal has a significant influence on the stress distribution around the weld. Similarly, by aplying both cyclic load or pre-stress load on the specimens, stress relaxation was observed even in the region of approximately $40 \mathrm{~mm}$ far from the weld toe.

\section{References}

1. P. Mikula, M. Vrána, L. Mráz and L. Karlsson, In Proc. Biennial ASME Conference on Engineering Systems Design and Analysis (ESDA 2008), 7 to 9 July 2008, Haifa, CD-ROM paper ESDA2008-59174.

2. L. Mráz, L. Karlsson, I. Hamák, P. Mikula, M. Vrána, In Proc. of the Internationl Conference "Experimental Stress Analysis" (EAN 2009), June 8-11, 2009, Sychrov, Edited by B. Marvalová, I. Petríková, L. Čapek, TU Liberec and Czech Society for Mechanics.

3. L. Mráz, 1. Karlsson, I. Hamák, M. Vrána and P. Mikula, Proc. of $1^{\text {st }}$ International Workshop on In-situ by synchroton and neutron diffraction, 1-2 September 2009, Berlin Germany.

a e-mail : mikula@ujf.cas.cz

This is an Open Access article distributed under the terms of the Creative Commons Attribution-Noncommercial License 3.0, which permits unrestricted use, distribution, and reproduction in any noncommercial medium, provided the original work is properly cited. 